\title{
EXAMINING THE MECHANICAL AND TRIBOLOGICAL BEHAVIOR OF AL-SIC COMPOSITE DEVELOPED BY CENTRIFUGAL CASTING TECHNIQUE
}

\section{ADEFEMI O. OWOPUTI", FREDDIE L. INAMBAO, \& WILLIAM S. EBHOTA}

Department of Mechanical Engineering University of KwaZulu-Natal, Durban, South Africa

\begin{abstract}
The increasing interest in functionally graded materials for automobile, military, and aerospace structural applications in recent years is due to its admirable properties such as good resistance to thermal fluctuation, good formability, and good strength. This study investigates the tribological property of aluminum A356 composites reinforced with silicon carbide particles with varied weight-percents and particle sizes fabricated through centrifugal casting technique. Tribological, mechanical, and SEM analyses were carried out on fabricated composite samples, reinforced with $\mathrm{SiC}_{p}$ of 7 $\mu$ and $15 \mu$ particle sizes, respectively. The results indicated that the insertion of the reinforcement particles in the aluminum matrix improved the microstructural properties of the fabricated composites and enhanced their tribological properties. Furthermore, this study confirms that the size of the reinforcement particles influences the overall properties of aluminium metal matrix composites.

KEYWORDS: Functionally graded materials, silicon carbide, frictional coefficient, tribology, aluminum matrix, centrifugal casting.
\end{abstract}

Received: Jan 03, 2021; Accepted: Jan 23, 2021; Published: Mar 08, 2021; Paper Id.: IJMPERDAPR202111

\section{INTRODUCTION}

Aluminum is the most abundant metal in the earth's crust. Its processing and use for industrial and domestic applications have significantly increased over the years. This increased application of aluminum and its alloys is not far removed from the excellent mechanical and tribological properties it possesses [1]. The ease of fabrication and relatively low cost also lend credence to its increased usage. Properties such as lightweight, low density, and toughness have also made alloys of aluminum the preferred material of choice in the automotive and aerospace industries [2]. However, in its pure state, aluminum is of little industrial use. Hence, the aluminum matrix composite concept introduces composites materials in controlled quantity into the aluminum matrix to improve its engineering properties such as abrasion resistance while leveraging on its excellent properties such as ductility and toughness $[3,4]$.

There have been various studies and research to develop a series of AMCs using different reinforcing materials such as $\mathrm{TiB}_{2}, \mathrm{SiC}, \mathrm{Al}_{2} \mathrm{O}_{3}, \mathrm{Mg}, \mathrm{Cu}, \mathrm{CNT}, \mathrm{ZnO}$, graphite, fly ash, and other elements. These reinforcing materials are adopted and used in varying weight-percent to produce a tailor-made material property suitable for specific applications [5, 6]. Furthermore, various manufacturing processes and techniques have been researched to fabricate the best materials for definite applications. The author has discussed these processes in a previous publication [7, 8]. AMCs have been found to possess a high strength to weight ratio and excellent tribological property, which makes them particularly suitable for structural, aerospace, and automobile application [9]. 
Functionally graded materials (FGMs) are materials with a gradient or varied concentration of reinforcement particles dispersed along the base material's matrix from one axis to the other. This advanced and novel material was developed to meet the ever-dynamic functional demands required in engineering applications such as low abrasion resistance, good machinability, thermal resistance, and the ability to withstand extreme and opposing conditions during service. FGM was birthed from a challenge to solve the thermal challenge faced by engineers from Japan when building the frame of a rocket in the mid-1980s. Since then, various FGM types have developed through several manufacturing techniques for automobile, military, aerospace, and structural applications.

The use of FGMs in the fabrication of automobile parts has been a focus for research in recent years, with different researchers exploring the potentials of various types of metal matrix composites (MMC) in solving specific automobile challenges. Polajnar, et al. [10] investigated the use of functionally graded ductile iron (FGDI), which contains $\mathrm{Cr}$ and $\mathrm{Ni}$ as reinforcing elements for brake pad application. Polajnar, et al. reported that improved wear property and a stable frictional coefficient were obtained on the FGDI due to the presence of the functionally graded zone and the formation of a thin oxidized layer on the pad, which aids in self-lubrication of the wear surface. Other researchers have also researched the use of Al-based MMC in the fabrication of FGMs [11-14]. Due to their high strength to weight ratio, low cost, and high wear resistance, aluminum matrix composites are widely manufactured and used in structural applications along with the aerospace and automobile industry. Also, a simple and cost-effective method for manufacturing the composites is essential for expanding their application. Reinforcements like particulate alumina, silicon carbide, graphite, fly ash, etc., can easily be incorporated into the melt using a simple yet innovative casting method.

Research into the various techniques and the development of novel ones in fabricating different metal-based FGMs have also garner keen interest among researchers. The prospect of components manufactured through CCT, as opposed to the conventional gravity casting for structural application, was demonstrated by Chirita, et al. [15]. They submitted that the FGM produced through centrifugal process possessed improved mechanical properties such as strength and toughness compared to those produced via gravity casting. Consequently, various researchers have adopted unique techniques to fabricate functionally graded metal-matrix composites tailor-made for specific engineering applications. Pawar and Utpat [16] developed FGMs for spur gear application using aluminum metal as the base matrix and silicon carbide particulate as the reinforcements while adopting a stir casting technique. The percentage weight addition of reinforcements utilized in producing the FGMs was varied from $2.5 \%$ to $10 \%$, and the variation's effect was examined. They submitted that properties of hardness and toughness of the FGMs were enhanced with increment in SiC reinforcement within the matrix.

In the quest to produce an ideal FGM suitable for any given application, researchers have studied the influence of various process parameters on specific mechanical behaviors desired of the FGM to be fabricated. A prime example of a mechanical property is the material's wear behavior.

The importance of the wear properties of engineering material used in automobile applications cannot be overstretched as moving parts in contact with each other are required to possess this property to mitigate uncontrolled material loss. The desire to improve on wear property of Al-based FGMs in automobile applications has necessitated the introduction of particle reinforcement such as silicon carbide into aluminum matrix to enhance this property. The adoption of silicon carbide as a choice reinforcing element for aluminum composites by various researchers stems from its relatively low cost, accessibility, and desirable abrasive properties. Silicon carbide particle exhibits a denser property compared to 
aluminum. When introduced into the aluminum matrix, properties such as abrasive strength and hardness of the resulting composite material are significantly improved [17]. Other influences of $\mathrm{SiC}$ addition to the aluminum matrix in varying amounts and under various fabrication techniques have been well researched and documented [18-21].

In research carried out by Pradhan, et al. [19], it was reported that the wear resistance of the aluminum metal matrix composite fabricated using the stir casting technique was greatly influenced by the addition of $\mathrm{SiC}$ reinforcements with controlled design parameter. Three sets of MMCs were fabricated and reinforced with $5 \mathrm{wt} . \%, 7.5 \mathrm{wt} . \%$, and $10 \mathrm{wt} \%$ of $\mathrm{SiC}$ particles. The pouring temperature for the cast was kept at $720^{\circ} \mathrm{C}$. Pradhan, et al. [19] reported a decrease in the frictional coefficient of reinforced MMC when compared to pure aluminum. Furthermore, a steady decrease in the frictional coefficients of the fabricated composites was observed as the weight-percent on the reinforcement increased.

Similarly, in the study conducted by Ozben, et al. [22], it was reported that the addition is $\mathrm{SiC}_{\mathrm{p}}$ as reinforcement to the $\mathrm{Al}$ matrix improved the strength and toughness of the composite material as the weight-percent is increased from 5\% to $15 \%$. However, beyond $10 \mathrm{wt} \%$, the composite's tensile strength gradually reduces as the material's hardness is observed to increase. Consequently, the wear behavior of the composite also reduces beyond $10 \mathrm{wt} . \%$ addition.

Other researchers have reported on the effect of other fabrication parameters such as stirring speed Nai and Gupta [23], pouring temperature, rotational speed, cooling rate, on other mechanical properties of FGMs produced through centrifugal and other casting methods. This paper seeks to highlight is the influence of SiC particle size on the mechanical and wear property of the FGAMMC manufactured using the centrifugal casting technique.

\section{EXPERIMENTAL PROCEDURES}

\section{Materials and Method}

Aluminum alloy A356 ingots and particles of $\mathrm{SiC}$ were adopted as the base materials and reinforcements respectively in the research. The average particle size of the $\mathrm{SiC}$ reinforcements was $7 \mu \mathrm{m}$ and $15 \mu \mathrm{m}$. Aluminum ingots were weighed and charged into the furnace and temperature set to $750{ }^{\circ} \mathrm{C}$ to melt the material. Dross formed on the melt was skimmed off while the $\mathrm{SiC}$ particle reinforcements are preheated in a muffle furnace to a temperature of $300{ }^{\circ} \mathrm{C}$ and introduced to the aluminum melt. Preheating is necessary to mitigate the rejection of the $\mathrm{SiC}$ particles from the melt due to a sharp temperature difference. Stirring the solution to enhance even dispersion of the $\mathrm{SiC}$ particles in the melt is carried out using a mechanical stirrer. The homogenous composite is poured into the cavity of a vertically rotated centrifugal machine for the casting process to begin. Due to the density difference between aluminum and silicon carbide, the centrifugal effect of the rotating mold was expected to force the $\mathrm{SiC}$ particles away from the center of the cast and towards the outer ends. Once solidification was completed, the cast sample was removed from the mold, and the process was repeated to produce other samples. Two sets of the sample were produced using two particle sizes of $\mathrm{SiC}_{\mathrm{p}}$ reinforcement $-7 \mu$ and $15 \mu$. Each set of the cast sample contained $1 \mathrm{wt} . \%, 3 \mathrm{wt} . \%$, and $5 \mathrm{wt} . \%$ addition of $\mathrm{SiC}_{\mathrm{p}}$. A control sample with $0 \mathrm{wt} . \%$ was also fabricated, bringing the cast samples to 7 . The cast samples were labeled from ' $\mathrm{A}$ ' to ' $\mathrm{G}$ ' were produced. The casting process parameters are shown in Table I, while Table II shows the chemical composition of the as-cast Al-356 and the reinforcement particles' chemical composition. As analyzed using the Bruker mass spectrometer, the samples' chemical compositions are presented in Table III. 
Table 1: Casting Parameters

\begin{tabular}{|l|l|}
\hline Melting temperature & $750{ }^{\circ} \mathrm{C}$ \\
\hline Melting Time & $10 \mathrm{Mins}$ \\
\hline Reinforcement preheated temp & $300^{\circ} \mathrm{C}$ \\
\hline Rotating speed of mold & $800 \mathrm{rpm}$ \\
\hline
\end{tabular}

Table 2: Chemical Composition of As-Cast Aluminium alloy and Rein Forcing SiC

\begin{tabular}{|l|c|c|c|c|c|c|}
\hline & Al & C & O & Fe & Si & Total \\
\hline $\begin{array}{l}\text { As-cast Aluminum Alloy (wt.\%) } \\
\text { (Sample D) }\end{array}$ & 92.3 & 5.83 & 1.52 & 0.36 & - & 100 \\
\hline Reinforcement (wt.\%) & - & 42.63 & 3.01 & - & 54.36 & 100 \\
\hline
\end{tabular}

Table 3: Chemical Compositions of the Cast Al-SiC Composites

\begin{tabular}{|c|c|c|c|c|c|c|}
\hline Sample & Wt. $\%, \mu \mathrm{m}$ & Si $(\%)$ & $\mathrm{C}(\%)$ & O (\%) & $\mathrm{Fe}(\%)$ & Al (\%) \\
\hline A & $1 \mathrm{wt} . \%, 7 \mu \mathrm{m}$ & 0.85 & 5.81 & 1.28 & 0.95 & Balance \\
\hline $\mathrm{B}$ & $3 \mathrm{wt} . \%, 7 \mu \mathrm{m}$ & 0.93 & 7.04 & 1.80 & 0.81 & Balance \\
\hline $\mathrm{C}$ & $5 \mathrm{wt} . \%, 7 \mu \mathrm{m}$ & 1.37 & 16.98 & 3.12 & 0.62 & Balance \\
\hline $\mathrm{D}$ & - & - & 5.83 & 1.52 & 0.36 & Balance \\
\hline $\mathrm{E}$ & $1 \mathrm{wt} . \%, 15 \mu \mathrm{m}$ & 0.80 & 5.84 & 1.30 & 0.87 & Balance \\
\hline $\mathrm{F}$ & $3 \mathrm{wt} . \%, 15 \mu \mathrm{m}$ & 0.87 & 7.08 & 1.85 & 0.69 & Balance \\
\hline $\mathrm{G}$ & 5 wt. $\%, 15 \mu \mathrm{m}$ & 1.29 & 16.85 & 3.24 & 0.48 & Balance \\
\hline
\end{tabular}

\section{Sample Preparation for Microstructural and Mechanical Analysis}

The cast samples produced from the casting process had dimensional configuration of $100 \mathrm{~mm}$ length and $20 \mathrm{~mm}$ diameter. The samples were sectioned and prepared for metallographic characterization. Each sectioned sample piece was mounted in Bakelite, and their surfaces were prepared using standard metallographic procedures. Grinding was carried out using 320-1200 grits of $\mathrm{SiC}$ grinding papers. Polishing was done using an automatic polishing machine with different microns of diamond suspensions and fumed silica on polishing cloths. The polishing process continued until a mirror-like surface was achieved. The samples' surfaces were further etched using Keller's reagent to reveal adequate details during the microstructural examination. The mechanical properties of hardness, tensile strength, and wear behavior of the FGM cast samples were also investigated. The individual sectioned samples were subjected to a hardness test to determine the effect of the different particle sizes with the varying concentrations of the reinforcement particles along each sample's length on their respective hardness properties. The hardness test was carried out using the LECO ${ }^{\circledR}$ M-400-H1 hardness testing machine with a load of $100 \mathrm{~g}$ and a dwell time of $15 \mathrm{sec}$. The hardness value for each sample was determined by taking the average values obtained from five indentations on the sample's surface to be examined. The uniquely developed FGAMMC presented in this paper was subjected to tribological analysis using a pin-on-disc Anton Paar tribometer. A stainless steel counterface with a surface roughness of $15 \mathrm{~nm}$, a load of $5 \mathrm{~N}$, a sliding distance of $400 \mathrm{~m}$, and a motor speed of $100 \mathrm{rev} / \mathrm{min}$ was used to determine the tribological property of the samples. The samples' worn surfaces were further examined using SEM to investigate the wear tracks formed and the interaction between the counterface material and samples' surface. 


\section{RESULTS AND DISCUSSIONS}

\section{Morphology of SiC Starting Powder}

The morphology of the SiC reinforcement was examined using SEM. Before this examination, the SiC particles were prepared by coating it with gold dust in a Quorum Q150A ES sputtering machine, which improves their conductivity. Figure 1 highlights the morphology of the reinforcement powders. The particles of Figure 1a and 1b displays a rocky and irregular shape. Several researchers have reported silicon carbide having a tetrahedral layer accompanied by a polyhedral structure. However, as observed in Figure 1a, the fragmented and elongated shape can be attributed to the crushing of the $\mathrm{SiC}$ particles into smaller sizes. The atoms of silicon carbide have been reported in literature to have a spacing of $1.46 \AA$ between the particles of silicon and carbon, which are the primary elements present in the powder.
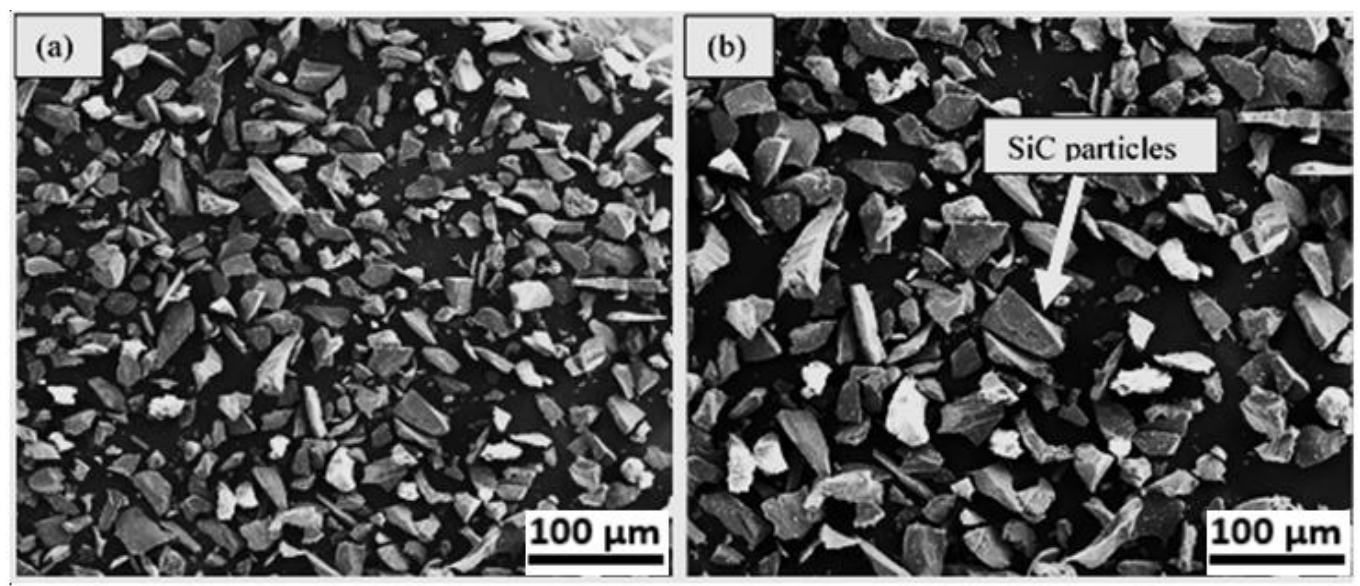

Figure 1: SEM Morphology of (a) $7 \mu \mathrm{m}$ and (b) $15 \mu \mathrm{m} \mathrm{SiC} \mathrm{Reinforcement} \mathrm{Particles}$

\section{Microstructural Analysis of FGM Samples}

The SEM morphology of the FGM samples is presented in Figure 2. Figure 2a shows the existence of the eutectic $\alpha$-Al phase, formed during the solidification of aluminum. The dendrites evident in the aluminum alloy matrix are less visible in the micrographs shown in Figure $2 \mathrm{~b}-2 \mathrm{~d}$. The reduction of dendrites can be ascribed to the incorporation of $\mathrm{SiC}$ reinforcement particles with varying particle sizes [24]. The homogeneous distribution of the reinforcement phases within the aluminum matrix is observed in Figure 2. Figures $2 b$ and $2 c$ with respective addition of 3 wt. $\%$ and 5 wt. $\%$ of $7 \mu$ SiC reinforcements show a clear interface and excellent bonding between the reinforcement and matrix phases, which could improve the load-bearing property of the fabricated composite during service. This observation is corroborated by the study carried out by Akinwamide, et al. [25]. The utilization of centrifugal casting is observed to be a successful technique as large sizes of SiC particles $(15 \mu)$ are seen to be effectively dispersed within the matrix of aluminum, as presented in Figure $2 \mathrm{~d}$. Furthermore, the level of strengthening offered by the reinforcement particles depends on factors, such as the particle size of reinforcement and the type of bond existing between the reinforcement and matrix phases [26]. 


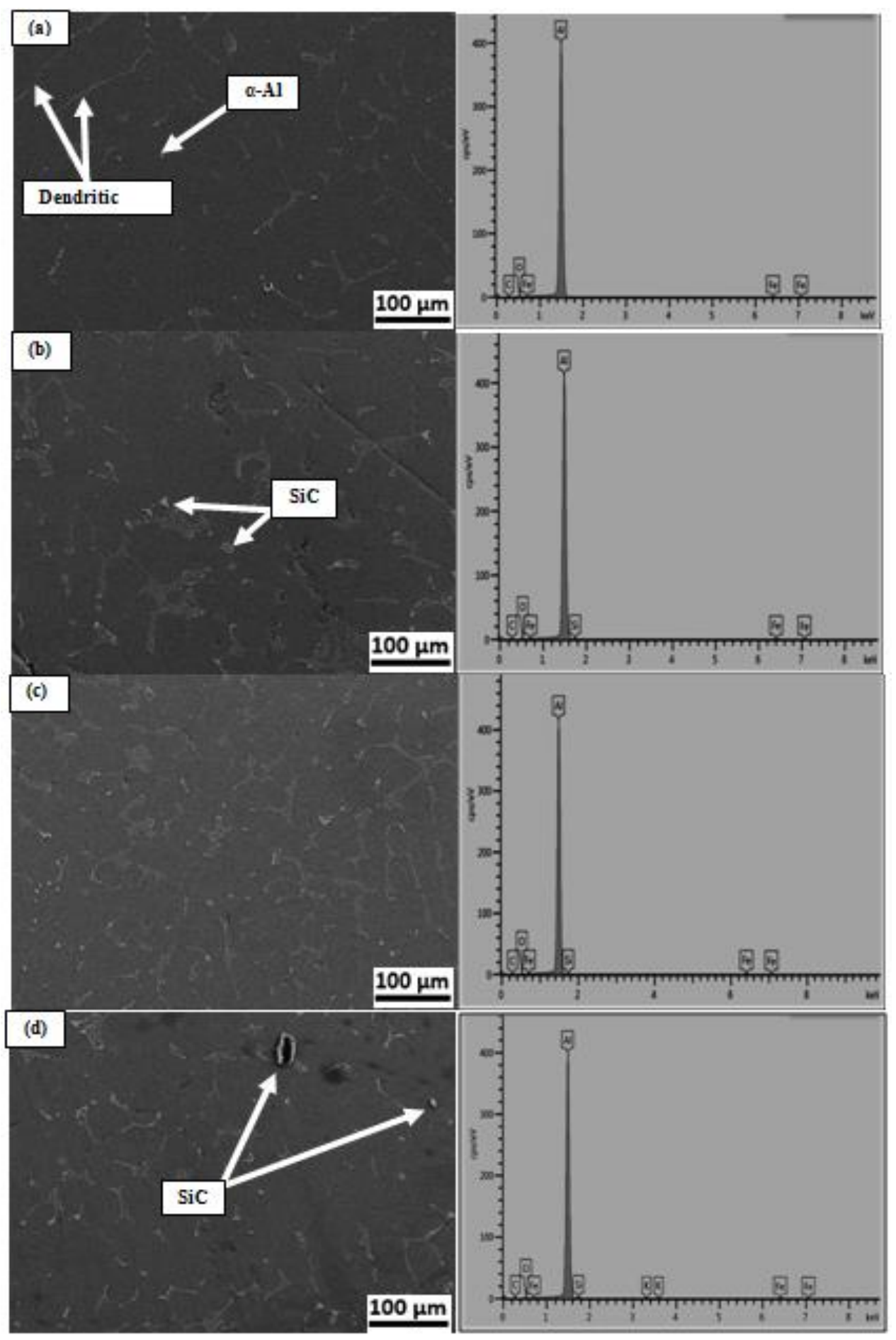

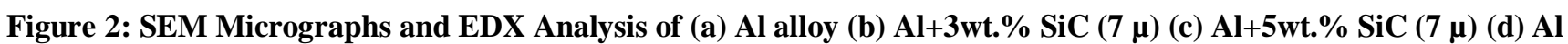
$+1 \mathrm{wt} . \% \mathrm{SiC}(15 \mu)$

\section{Mechanical Properties of Al- 356 FGM}

In a previous study, the authors have been able to establish the effect of particle size and percentage weight concentration of the $\mathrm{SiC}$ reinforcements within the matrix of the aluminum A356 alloy on the mechanical properties of hardness tensile strength. Samples A, B, and C were reinforced with SiC particles with an average size of $7 \mu$ at 1 wt.\%, 3 wt.\%, and 5 wt.\% of the aluminum A356 alloys. The cast samples were observed to possess hardness values of 106.8 HV100, 111 
HV100, and 112.7 HV100, respectively. Sample D (control), with no reinforcement added to it, exhibited a hardness value of $102 \mathrm{HV} 100$. Furthermore, samples E, F, G, which contained SiC reinforcements of average particle size of $15 \mu \mathrm{m}$ at 1 wt.\%, 3 wt.\%, and 5 wt.\% of the Al-356 alloys, showed hardness values of 104 HV100, 106.1 HV100, and 108.4 HV100, respectively. Using the cast composite samples' obtained hardness values, corresponding tensile strength values were calculated with the aid of an online engineering software database [27]. Tensile strength values obtained were crossreferenced with values obtained from the ASTM A370 / ASME SA-370 standard manual, and a strong relationship was established [21, 28]. The influence of the difference in SiC particle sizes on the matrix of cast aluminium composite in the mechanical properties (tensile and hardness) was fully established in the previously published articles. The reinforced composites with the larger particle size of $\mathrm{SiC}$ reinforcements $(15 \mu)$ recorded reduced mechanical properties as it allows easy movement of dislocation. However, the improved mechanical properties exhibited by the cast samples that were reinforced with $7 \mu \mathrm{SiC}$ particles are attributed to excellent bonding and the effective load-bearing mechanism characteristic of the smaller size reinforcement particles.

\section{Frictional Coefficient of as-Cast Aluminum Alloy and Composites}

The plot of the coefficient of friction of samples with $7 \mu$ and $15 \mu$ particle sizes against sliding time is shown in Figure 3 and Figure 4, respectively. From Figure 3, the lowest frictional coefficient is evident in the sample without any reinforcement particle $(0 \mathrm{wt} . \%)$. The sudden rise in the frictional coefficient observed in the sample after the first $80 \mathrm{~s}$ can be ascribed to heat generation between the stainless-steel counterface and the sample [29]. However, a uniform trend with increased fluctuation, observed in the samples with 1 wt.\%, 3 wt.\%, and 5 wt.\% SiC particles can be attributed to a reduction in the abrasive force generated between the two surfaces in contact during the test [30]. The slight increase in the frictional coefficient of the sample reinforced with $3 \mathrm{wt} \% \mathrm{SiC}$ reinforcement after the first $300 \mathrm{~s}$ is due to the rapid removal of the surface layer resulting from the contact between the sample surface and the counterface ball. This observation is in agreement with a study by Akinwamide et al. [31]. Figure 4 shows the dispersion effect of varying proportions of $15 \mu \mathrm{SiC}$ particles on the samples' resistance to wear under a static load. The sturdy fluctuations observed in the sample reinforced with $1 \mathrm{wt} . \% \mathrm{SiC}$ particles can be a result of contact between the dispersed large-sized SiC particles and the stainless steel counterface ball. This is in contrast with a uniform trend observed in the samples reinforced with higher proportions of SiC particles ( $3 \mathrm{wt} . \%$ and $5 \mathrm{wt} . \%$ ). The higher frictional coefficient recorded by the samples with reinforcements results from the repeated generation of heat and opposition offered by the reinforcement particles to the sliding of the stainless steel counterface over the sample surface [32]. It should also be noted that SiC particles have been reported to assist with forming passive films on the surface of the reinforced samples, thereby decreasing the rate of wear during metal to metal interaction. [33, 34]. 


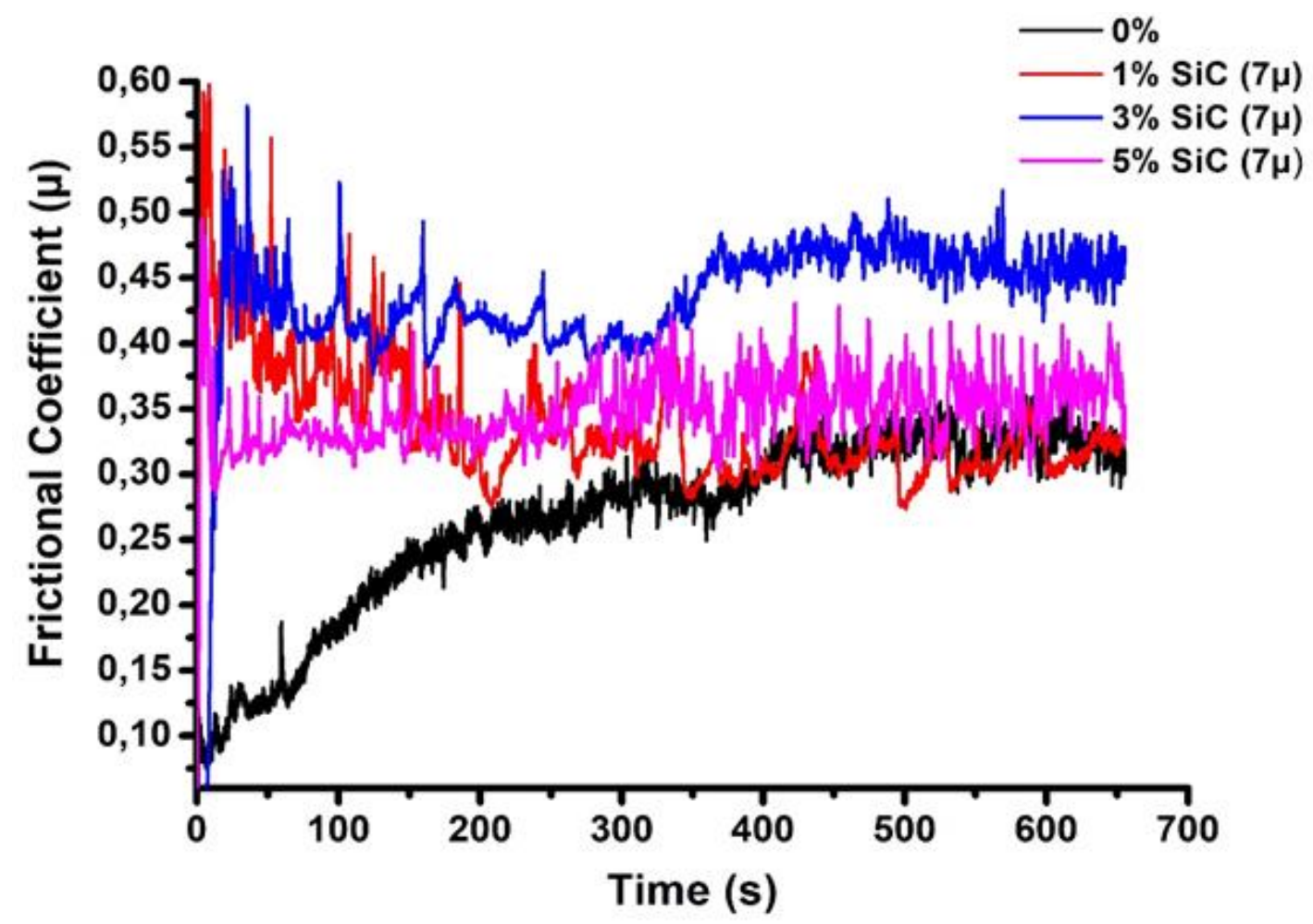

Figure 3: Frictional Coefficient of as-Cast Aluminium Alloy and composites with $7 \boldsymbol{\mu}$ SiC reinforcements

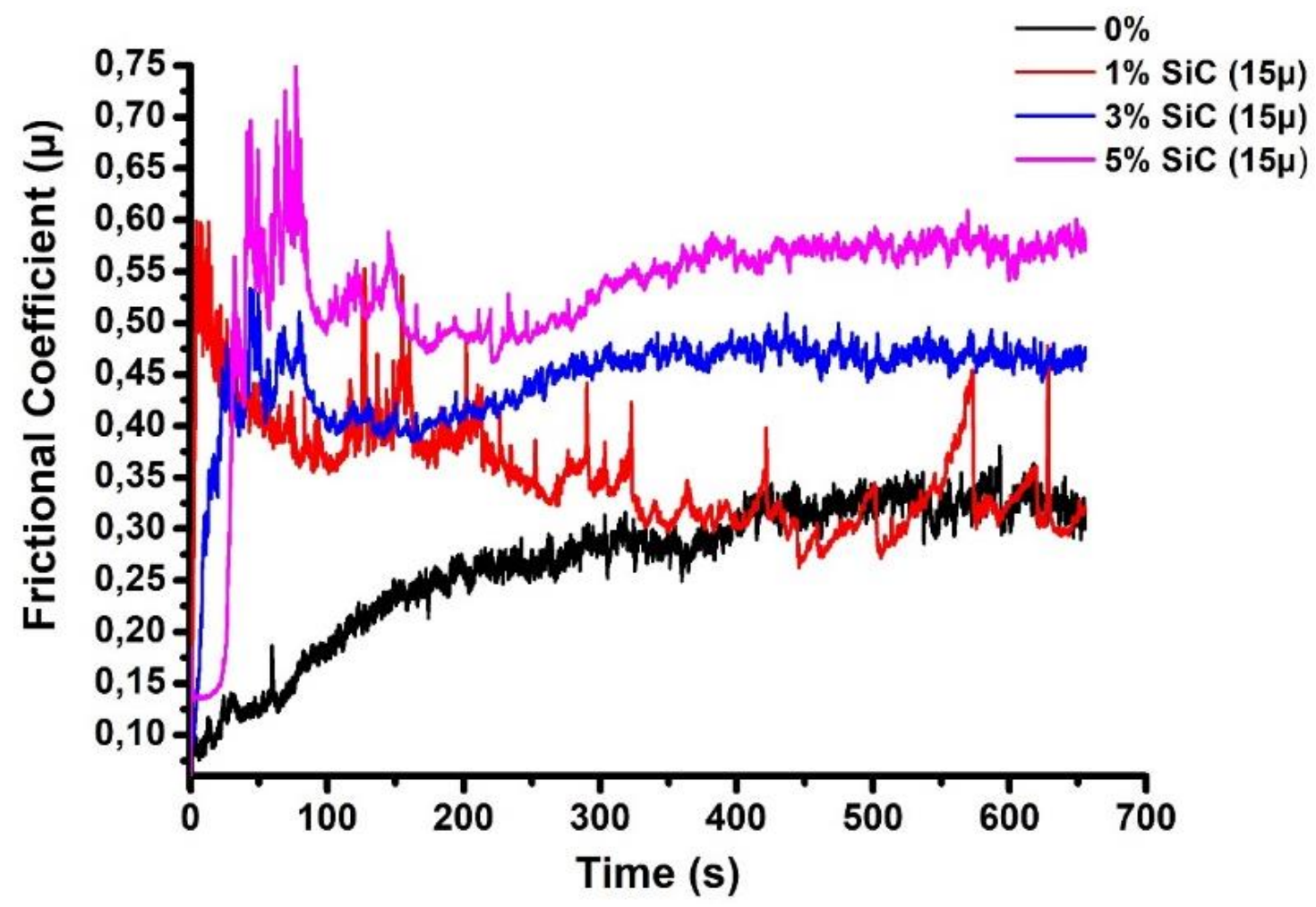

Figure 4: Frictional Coefficient of as-Cast Aluminum Alloy and Composites with $15 \mu \mathrm{SiC}$

The SEM of the wear tracks formed from the interaction between the sample surface and the tribometer pin are shown in Figure 5. Figure 5a shows that the plastic deformation of the unreinforced alloy, leading to the sample surface's delamination, is evident. The grooves visible across the wear track indicate abrasive wear [32, 35]. Figure 5b-5c shows a 
laminar flow that resulted from ductile shearing on the wear tracks. Consequently, the samples' surfaces were damaged due to the $\mathrm{SiC}$ particles' resistance to the tribometer pin's sliding movement on the surfaces [36]. The formation of chippings resulting from the continuous ploughing surface of the samples containing larger size SiC particle reinforcements was observed. Similar chip formations have previously been reported in a study by Dwivedi [37]
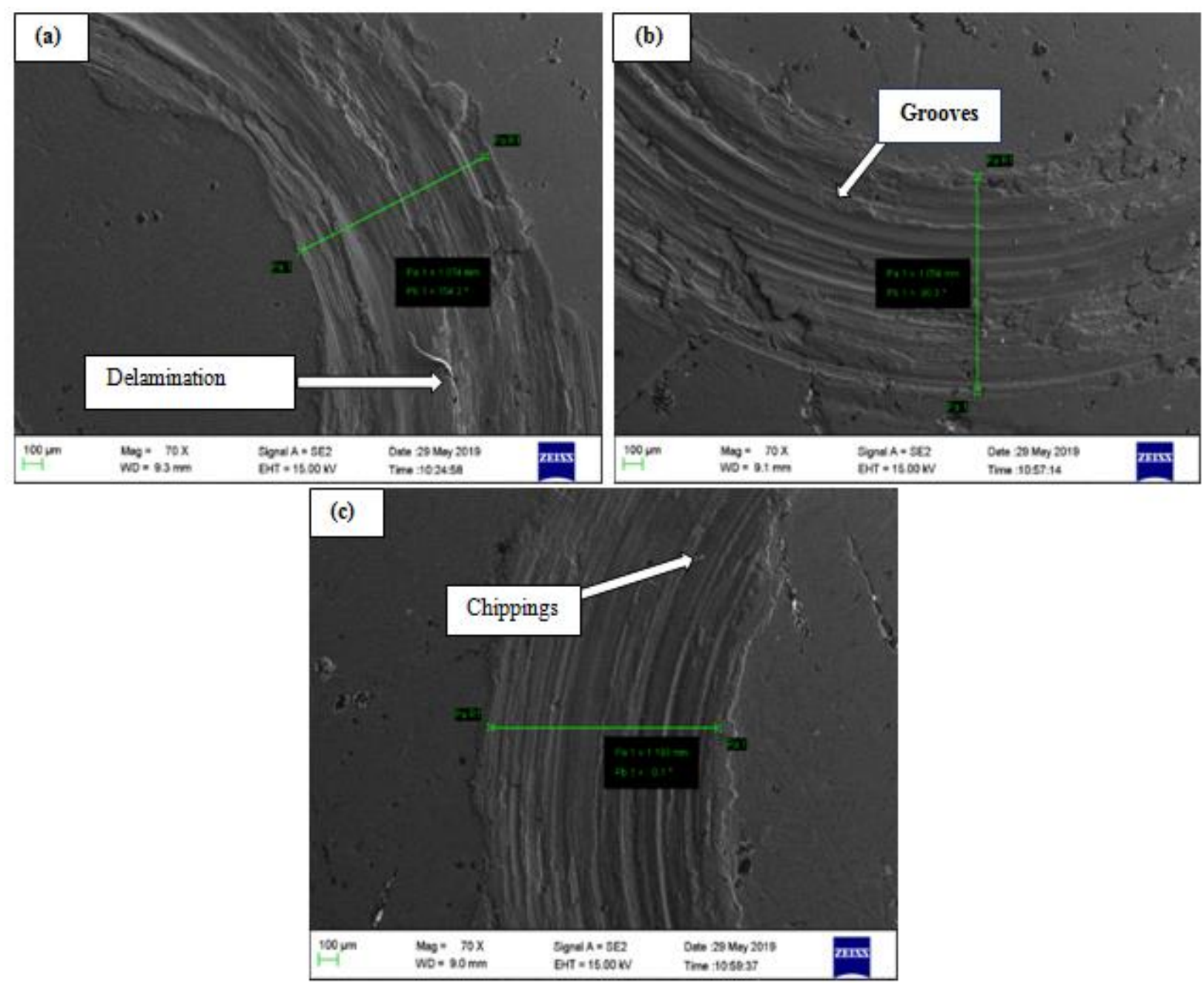

Figure 5: Wear Tracks of (a) Al alloy (b) Al + 3 wt.\% SiC (7 $\mu$ ) (c) Al + 3 wt.\% SiC (15 $\mu)$

\section{CONCLUSIONS}

The effect of the varying particle size on the microstructural and tribological properties of $\mathrm{Al}$ alloy and $\mathrm{SiC}_{\mathrm{p}}$ was investigated in this study, and the following conclusions were made.

- An improved bonding interface was observed in the composite reinforced with $7 \mu$ when compared to composites reinforced with $15 \mu$. This was confirmed by the microstructural and mechanical analysis performed on the samples.

- The incorporation of $\mathrm{SiC}$ particles as reinforcement into the aluminum matrix resulted in an increased heat generation on the surface of the samples during the tribological test. This indicates that the particles of SiC offered significant resistance to the sliding force from the stainless steel counterface. 
- The improvement in the tribological property of reinforced composites was ascribed to the formation of thin oxide layer on the surface of the composite.

- Resistance to the sliding movement of the tribology pin on the samples' surface was observed to be greater in the composites with $7 \mu$ reinforcement particle size than in composites with $15 \mu$ reinforcement particle sizes

\section{Conflict of Interest}

The authors declare no conflict of interest associated with this study.

\section{ACKNOWLEDGMENT}

The authors will like to acknowledge the support and contribution of the Department of Mechanical Engineering of the University of KwaZulu-Natal to the success of this study.

\section{REFERENCES}

1. S. O. Akinwamide, "Study of Microstructural and Mechanical Properties of Stir Cast Al (SiC-Mg-TiFe) Composite," Fluid Dynamics \& Materials Processing, vol. 15, no. 1, pp. 15-26, 2019.

2. S. A. Raj, D. C. Jana, P. Barick, and B. P. Saha, "Microstructure evolution in densification of SiC ceramics by aluminium vapour infiltration and investigation of mechanical properties, "Ceramics International, vol. 44, no. 8, pp. 9221-9226, 2018.

3. G. E. Kiourtsidis, S. M. Skolianos, and G. A. Litsardakis, "Aging response of aluminium alloy 2024/silicon carbide particles (SiCp) composites," Materials Science and Engineering: A, vol. 382, no. 1-2, pp. 351-361, 2004.

4. J. Oghenevweta, V. Aigbodion, G. Nyior, and F. Asuke, "Mechanical properties and microstructural analysis of Al-SiMg/carbonized maize stalk waste particulate composites, "Journal of King Saud University-Engineering Sciences, vol. 28, no. 2, pp. 222-229, 2016.

5. D. Gopi, E. Shinyjoy, M. Sekar, M. Surendiran, L. Kavitha, and T. S. Sampath Kumar, "Development of carbon nanotubes reinforced hydroxyapatite composite coatings on titanium by electrodeposition method," Corrosion Science, vol. 73, pp. 321 330, 2013/08/01/2013, doi: https://doi.org/10.1016/j.corsci.2013.04.021.

6. Z. Qasim, M. Jabbar, and J. Hassan, "Enhancement the mechanical properties of aluminum casting alloys (A356) by adding nanorods structures from zinc oxide," J Mater. Sci. Eng, vol. 6, no. 2, pp. 2-5, 2017.

7. A. O. Owoputi, F. L. Inambao, and W. S. Ebhota, "A Review of Functionally Graded Materials: Fabrication Processes and Applications," International Journal of Applied Engineering Research, vol. 13, no. 23, pp. 16141-16151, 2018.

8. F. V. Adams, S. O. Akinwamide, B. Obadele, and P. A. Olubambi, "Comparison study on the corrosion behavior of aluminum alloys in different acidic media," Materials Today: Proceedings, 2020.

9. H. Kala, K. K. S. Mer, and S. Kumar, "A Review on Mechanical and Tribological Behaviors of Stir Cast Aluminum Matrix Composites," Procedia Materials Science, vol. 6, pp. 1951-1960, 2014/01/01/ 2014, doi: https://doi.org/10.1016/j.mspro.2014.07.229.

10. M. Polajnar, M. Kalin, I. Thorbjornsson, J. T. Thorgrimsson, N. Valle, and A. Botor-Probierz, "Friction and wear performance of functionally graded ductile iron for brake pads," Wear, vol. 382-383, pp. 85-94, 2017, doi: https://doi.org/10.1016/j.wear.2017.04.015. 
11. S. V. Prasad and R. Asthana, "Aluminum Metal-Matrix Composites for Automotive Applications: Tribological Considerations," Tribology Letters, journal article vol. 17, no. 3, pp. 445-453, October 01 2004, doi: 10.1023/B:TRIL.0000044492.91991.f3.

12. A. Bouzekova-Penkova and A. Miteva, "Aluminium-Based Functionally Graded Materials."

13. I. El-Galy, M. Ahmed, and B. Bassiouny, "Characterization of functionally graded Al-SiCp metal matrix composites manufactured by centrifugal casting," Alexandria Engineering Journal, vol. 56, no. 4, pp. 371-381, 2017.

14. M. Sukruth, K. Chethan, and K. Aithal, "Study of Functionally Graded Al-Si Alloy Fabricated by Centrifuge Casting Technique," IJASRE, vol. 3, 2017.

15. G. Chirita, D. Soares, and F. Silva, "Advantages of the centrifugal casting technique for the production of structural components with Al-Si alloys," Materials \& Design, vol. 29, no. 1, pp. 20-27, 2008.

16. P. B. Pawar and A. A. Utpat, "Development of Aluminium Based Silicon Carbide Particulate Metal Matrix Composite for Spur Gear," Procedia Materials Science, vol. 6, pp. 1150-1156, 2014, doi: https://doi.org/10.1016/j.mspro.2014.07.187.

17. A. Mazahery and M. O. Shabani, "Microstructural and abrasive wear properties of SiC reinforced aluminum-based composite produced by compocasting," Transactions of Nonferrous Metals Society of China, vol. 23, no. 7, pp. 1905-1914, 2013.

18. V. S. Aigbodion and S. B. Hassan, "Effects of silicon carbide reinforcement on microstructure and properties of cast Al-SiFe/SiC particulate composites," Materials Science and Engineering: A, vol. 447, no. 1, pp. 355-360, 2007/02/25/2007, doi: https://doi.org/10.1016/j.msea.2006.11.030.

19. S. Pradhan, T. K. Barman, P. Sahoo, and G. Sutradhar, "Effect of SiC weight percentage on tribological properties of Al-SiC metal matrix composites under acid environment," Jurnal Tribologi, vol. 13, pp. 21-35, 2017.

20. R. Rao and S. Das, "Effect of matrix alloy and influence of SiC particle on the sliding wear characteristics of aluminium alloy composites, "Materials \& Design, vol. 31, no. 3, pp. 1200-1207, 2010.

21. A. O. Owoputi, F. L. Inambao, and W. S. Ebhota, "Influence of SiCp Reinforcement on the Mechanical Properties of Functionally Graded Aluminum Metal Matrix Composites Fabricated by Centrifugal Casting Technique," International Journal of Mechanical Engineering and Technology, vol. 10, no. 8, pp. 306-316, 2019. [Online]. Available: http://www.iaeme.com/IJMET/issues. asp? JType=IJMET\&VType $=10 \& I T y p e=8$.

22. T. Ozben, E. Kilickap, and O. Çakır, "Investigation of mechanical and machinability properties of SiC particle reinforced AlMMC," Journal of Materials Processing Technology, vol. 198, no. 1, pp. 220-225, 2008/03/03/ 2008, doi: https://doi.org/10.1016/j.jmatprotec.2007.06.082.

23. S. Nai and M. Gupta, "Influence of stirring speed on the synthesis of Al/SiC based functionally gradient materials, " Composite Structures, vol. 57, no. 1-4, pp. 227-233, 2002.

24. Y. Saberi, S. M. Zebarjad, and G. H. Akbari, "On the role of nano-size SiC on lattice strain and grain size of Al/SiC nanocomposite," Journal of alloys and compounds, vol. 484, no. 1-2, pp. 637-640, 2009.

25. S. O. Akinwamide, M. Lesufi, O. J. Akinribide, P. Mpolo, and P. A. Olubambi, "Evaluation of microstructural and nanomechanical performance of spark plasma sintered TiFe-SiC reinforced aluminium matrix composites," Journal of Materials Research and Technology, vol. 9, no. 6, pp. 12137-12148, 2020.

26. A. F. Boostani et al., "Enhanced tensile properties of aluminium matrix composites reinforced with graphene encapsulated SiC nanoparticles," Composites Part A: Applied Science and Manufacturing, vol. 68, pp. 155-163, 2015. 
27. C. Wu, V. Kumar, J. Liau, F. L'Esperance, and G. Baker. "Efunda Hardness List." https://www.efunda.com/units/hardness/show_hardness.cfm (accessed 26 June, 2019).

28. A. O. Owoputi, F. L. Inambao, and W. S. Ebhota, "Effect of percentage weight and particle size of SiCp reinforcement on the mechanical behaviour of functionally graded aluminum metal matrix," International Journal of Engineering Research and Technology, vol. 13, no. 3, pp. 444-453. [Online]. Available: http://www.irphouse.com/ijert20/ijertv13n3_10.pdf.

29. S. Prasad and R. Asthana, "Aluminum metal-matrix composites for automotive applications: tribological considerations," Tribology letters, vol. 17, no. 3, pp. 445-453, 2004.

30. S. Saravanan, M. Senthilkumar, and S. Shankar, "Effect of particle size on tribological behavior of rice husk ash-reinforced aluminum alloy (AlSi10Mg) matrix composites," Tribology transactions, vol. 56, no. 6, pp. 1156-1167, 2013.

31. S. O. Akinwamide, S. M. Lemika, B. A. Obadele, O. J. Akinribide, B. T. Abe, and P. A. Olubambi, "Characterization and mechanical response of novel Al-(Mg-TiFe-SiC) metal matrix composites developed by stir casting technique," Journal of Composite Materials, vol. 53, no. 28-30, pp. 3929-3938, 2019.

32. L. F. Xavier and P. Suresh, "Wear behavior of Aluminium Metal Matrix Composite prepared from industrial waste," The Scientific World Journal, vol. 2016, 2016.

33. N. Radhika and R. Raghu, "Development of functionally graded aluminium composites using centrifugal casting and influence of reinforcements on mechanical and wear properties," Transactions of Nonferrous Metals Society of China, vol. 26, no. 4, pp. 905-916, 2016.

34. S. O. Akinwamide, B. T. Abe, O. J. Akinribide, B. A. Obadele, and P. A. Olubambi, "Characterization of microstructure, mechanical properties and corrosion response of aluminium-based composites fabricated via casting-a review," The International Journal of Advanced Manufacturing Technology, 2020/07/10 2020, doi: 10.1007/s00170-020-05703-1.

35. C. Ramesh, R. Keshavamurthy, B. Channabasappa, and A. Ahmed, "Microstructure and mechanical properties of Ni-P coated Si3N4 reinforced Al6061 composites," Materials Science and Engineering: A, vol. 502, no. 1-2, pp. 99-106, 2009.

36. S. O. Akinwamide, O. J. Akinribide, and P. A. Olubambi, "Microstructural evolution, mechanical and nanoindentation studies of stir cast binary and ternary aluminium based composites, " Journal of Alloys and Compounds, p. 156586, 2020.

37. D. Dwivedi, "Adhesive wear behaviour of cast aluminium-silicon alloys: Overview, Materials \& Design (1980-2015), vol. 31, no. 5, pp. 2517-2531, 2010. 